\title{
Smoking mothers and snuffing fathers: behavioural influences on youth tobacco use in a Swedish cohort
}

\author{
K I Rosendahl, M R Galanti, H Gilliam, A Ahlbom
}

Tobacco Control 2003;12:74-78

\begin{abstract}
Objective: To analyse the influences of parental use of cigarettes and snus (the Swedish variety of smokeless tobaccol on offspring's behaviour.

Design: Prospective cohort study.

Setting: The Stockholm County of Sweden.

Subjects: 2232 adolescents recruited in the fifth grade (mean age 11.6 years) with follow up in the eighth grade.

Main outcome measures: Self reported tobacco use (ever and current use of cigarettes and/or snus) in the eighth grade.

Results: Parents' tobacco use was associated with adolescents' current use of cigarettes and snus lodds ratio (OR) 2.7, 95\% confidence interval (Cl) 1.8 to 3.9 if both parents used tobacco $v$ neither parent). Mother's cigarette smoking was associated with adolescents' current exclusive smoking (OR $2.4,95 \% \mathrm{Cl} 1.6$ to 3.6). Father's use of snus was associated with current exclusive use of snus among boys (OR 3.0,95\% Cl 1.4 to 6.4), but not with current cigarette use. The overall prevalence of current smoking was lower among children whose fathers used snus than among those whose fathers smoked. Conclusions: Parental smoking, especially maternal smoking, enhances the risk of tobacco experimentation in youths, as does paternal use of smokeless tobacco. However, the transition to regular cigarette smoking is not likely to be affected by paternal use of smokeless tobacco. Contextual factors, in particular declining smoking trends and negative social acceptance of smoking, can explain most of these findings.
\end{abstract}

See end of article for authors' affiliations

Correspondence to: Ingrar Rosendahl, Center for Tobacco Prevention, Stockholm Center of Public Health, PO Box 17533, SE-11891 Stockholm, Sweden;

ingvar.rosendahl@smd.sll.se

Received 6 May 2002.

Accepted

11 December 2002

$\mathrm{P}$ arents' lifestyles are believed to be of importance in influencing offspring's health behaviour. ${ }^{1}$ Parental cigarette smoking is associated with increased likelihood that the child also smokes. ${ }^{2}$ This association was not always consistent across studies, discrepancies most probably depending on different populations and outcomes under study. Several similarities exist between smoking and smokeless tobacco (ST) use among adolescents. ${ }^{3}$ The use of both tobacco products has been associated with use of alcohol and marijuana. ${ }^{4}$ Associations between use of either tobacco product and corresponding use among peers, siblings and parents has also been reported. However, the question whether the use of a specific product and the sex of the parent display different influences on the corresponding behaviour in adolescents (cross influences) has not been systematically investigated. Moreover, the use of tobacco has seldom been analysed in mutually exclusive behavioural categories. ${ }^{35}$ Finally, most evidence rests on cross sectional studies. ${ }^{6}$

The patterns of ST use and cigarette smoking differ across countries and social groups, as probably do family influences. There are several reasons to hypothesise that in Sweden the family influences on youth tobacco use may be atypical. First, the use of ST among Swedish men is currently (2000) more frequent than cigarette smoking (20\% and $18 \%$ of daily users, respectively), ${ }^{7}$ representing the highest prevalence in the western world. ${ }^{8}$ Among women, on the other hand, only 1\% use ST daily, while $23 \%$ smoke cigarettes. ${ }^{7}$ Second, the Swedish variety of ST (the moist, non-fermented, oral tobacco "snus") differs from other similar products in several respects, the most important of which probably is its relatively low content of tobacco specific nitrosamines (TSNA). ${ }^{9}$ Because of the lack of conclusive evidence of snus causing major deleterious health effects, ${ }^{10}$ the product is regarded as a "safer" alternative to cigarettes by an increasing proportion of the population. ${ }^{11}$ If parental use of ST would represent a risk factor for taking up cigarette smoking during adolescence the concern for public health would be evident, both in terms of public education and of adult tobacco cessation strategies. The objective of this longitudinal study was to disentangle the influence of different patterns of parental tobacco use on adolescents' corresponding behaviour, in a setting where the social norms around cigarette smoking and ST are increasingly diverging.

\section{METHODS AND MATERIALS}

Information on the study population and methods in the BROMS study has been previously published ${ }^{12}$ and will only be summarised here. A cohort of 3019 adolescents was recruited in the fifth grade (mean (SD) age 11.6 (0.33) years), through a random sample of schools in the Stockholm region. The study base in this study consists of adolescents who in 1998 completed the baseline and in 2001 the eighth grade assessment form, had not yet tried tobacco at baseline, and lived with at least one parent at that time $(n=2232)$. Use of cigarettes and snus was investigated by separate sets of questions aimed to assess lifetime and current use of either type of tobacco. Lifetime use was assessed by the questions "Did you ever try cigarette smoking, even a few puffs?", and "Did you ever try snus?" with dichotomous response alternatives. Current use was assessed by the questions "Do you smoke now?", and "Do you use snus now?" with the following five response alternatives: not at all; occasionally, but not monthly; monthly, but not weekly; weekly, but not daily; daily.

Information on parents' tobacco use, and on their sociodemographic characteristics, such as occupation and

Abbreviations: BROMS, Swedish acronym for Children's Smoking and Environment in the Stockholm County, $\mathrm{Cl}$, confidence interval, OR, odds ratio, ST, smokeless tobacco; TSNA, tobacco specific nitrosamines 
Table 1 Tobacco use among the adolescents in eighth grade

\begin{tabular}{lrrrrr}
\hline & \multicolumn{2}{c}{ Boys $(\mathrm{n}=1066)$} & \multicolumn{2}{c}{ Girls $(\mathrm{n}=1166)$} \\
\cline { 2 - 3 } Tobacco use & Number* \% & & \multicolumn{2}{c}{ Number* \% } \\
\hline Ever use & 455 & 42.7 & 477 & 40.0 \\
$\quad$ No tobacco & 145 & 13.6 & 87 & 7.5 \\
Snus only & 191 & 17.9 & 380 & 32.6 \\
Cigarette smoking only & 275 & 25.8 & 222 & 19.0 \\
$\quad$ Both snus and cigarette smoking & & & & \\
Current use & 805 & 88.6 & 918 & 87.8 \\
$\quad$ No tobacco & 40 & 4.4 & 1 & 0.1 \\
Snus only & 29 & 3.2 & 124 & 11.8 \\
Cigarette smoking & 35 & 3.8 & 3 & 0.3 \\
Both snus and cigarette smoking & 35 & & & \\
\hline
\end{tabular}

*The figures do not add up to the total for the current use because of missing information.

education, was collected at baseline and again in the seventh grade, through a self completed mail questionnaire. Parents' forms were available for 2218 (99\%) subjects of the study base at baseline and 2110 (95\%) in the seventh grade. Parental current use of tobacco was assessed as each parent's use of cigarettes and snus, according to three predefined categories: no use; occasional use; daily use. In the seventh grade survey, parents' previous use of either type of tobacco was also investigated (that is, whether they were former users and quit year).

\section{Data analysis and statistical methods}

Ever and current use of either type of tobacco were the outcomes of interest in this analysis. Ever users were subjects who anytime had tried snus or cigarettes. Those who reported at least monthly use were considered current users. A broad definition of current users was employed, because of the low frequency of subjects reporting current use, especially of snus. Adolescents' behaviour was analysed as use of cigarettes, snus or any tobacco product and categorised into four mutually exclusive categories: no tobacco use; snus only; cigarette smoking only; combined use of snus and cigarettes. The same categorisation was also used for parental behaviour (the exposure of interest in this analysis). In addition, for both parental cigarette smoking and overall tobacco use a cumulative indicator of exposure was analysed, as follows: neither parent smokes/uses tobacco; one parent smokes/uses tobacco; both parents smoke/use tobacco. By combining the information on each parent's current and past tobacco use we derived a dichotomous index of adolescents' lifetime exposure as never (parent never used tobacco or stopped before the child's birth) or ever (parent used tobacco sometime during the child's life).

The following factors were used for adjustment in all analyses: age, sex, whether the parents lived together, whether either parent was born abroad, parents' socioeconomic status, and tobacco use among friends. Parents' socioeconomic status was categorised primarily as to mother's education (elementary school, senior high school, college or higher). If the information on mother's education was not available we used father's education. When information on education was missing for both parents ( $2 \%$ of the subjects) we used educational level required for the employment in the current job position. Friends' tobacco use was dichotomously categorised as "no" versus "at least one" friend using tobacco. The association with each parent's behaviour was also adjusted for the other parent's overall tobacco use (any $v$ none). The analysis of current use of snus was restricted to boys as this behaviour was very rare among girls.

As measure of association we calculated the odds ratios (OR) of adolescents' tobacco use according to exposure to
Table 2 Adolescents' exclusive use of snus and cigarettes or the combination of both tobacco products in relation to exposure to parental tobacco use in the study cohort

\begin{tabular}{|c|c|c|c|c|}
\hline \multirow[b]{2}{*}{ Exposure to: } & \multirow{2}{*}{$\begin{array}{l}\text { Number of } \\
\text { adolescents* } \\
(n=2232)\end{array}$} & \multicolumn{3}{|c|}{ Adolescents current use (\%) of: } \\
\hline & & Snus & Cigarettes & Both \\
\hline \multicolumn{5}{|c|}{ Mother's current smoking } \\
\hline No & 1695 & 1.9 & 6.4 & 1.6 \\
\hline Yes & 350 & 3.1 & 13.0 & 2.8 \\
\hline \multicolumn{5}{|c|}{ Father's current smoking } \\
\hline No & 1676 & 2.0 & 7.1 & 1.6 \\
\hline Yes & 440 & 2.4 & 10.1 & 3.7 \\
\hline \multicolumn{5}{|c|}{ Mother's current use of snus } \\
\hline No & 2071 & 1.9 & 7.8 & 2.0 \\
\hline Yes & 44 & 8.1 & 5.4 & 0.0 \\
\hline \multicolumn{5}{|c|}{ Father's current use of snus } \\
\hline No & 1651 & 1.6 & 7.6 & 1.9 \\
\hline Yes & 436 & 4.3 & 8.3 & 2.7 \\
\hline \multicolumn{5}{|c|}{ Parents' current smoking } \\
\hline Neither & 1399 & 1.9 & 5.6 & 1.5 \\
\hline One & 520 & 2.2 & 13.1 & 2.0 \\
\hline Both & 183 & 3.3 & 10.0 & 4.7 \\
\hline \multicolumn{5}{|c|}{ Parents' current tobacco use } \\
\hline Neither & 1132 & 1.5 & 5.2 & 1.6 \\
\hline One & 653 & 1.9 & 11.4 & 1.8 \\
\hline Both & 283 & 5.1 & 9.8 & 3.8 \\
\hline \multicolumn{5}{|c|}{ Mother's anytime smoking } \\
\hline Never & 1210 & 1.7 & 4.9 & 2.0 \\
\hline Ever & 874 & 3.0 & 11.9 & 1.9 \\
\hline \multicolumn{5}{|c|}{ Father's anytime smoking } \\
\hline Never & 1176 & 1.6 & 6.0 & 1.3 \\
\hline Ever & 793 & 2.9 & 9.6 & 3.3 \\
\hline \multicolumn{5}{|c|}{ Mother's anytime use of snus } \\
\hline Never & 1781 & 1.9 & 7.3 & 2.0 \\
\hline Ever & 76 & 6.6 & 9.8 & 0.0 \\
\hline \multicolumn{5}{|c|}{ Father's anytime use of snus } \\
\hline Never & 1294 & 1.5 & 7.4 & 1.8 \\
\hline Ever & 603 & 3.8 & 7.6 & 2.5 \\
\hline
\end{tabular}

parental tobacco use. We analysed multiple category outcomes (that is, no tobacco use; use of snus only; cigarette smoking only; both snus use and cigarette smoking) by means of multinomial logistic regression. This method is an extension of the binary logistic regression, especially suitable for outcomes on an ordinal scale. It estimates the odds of being in each of the more extreme outcome categories rather than in the lowest one, according to values of the predictor variables. ${ }^{13}$ In order to estimate precision the $95 \%$ confidence intervals (CI) were calculated around OR.

\section{RESULTS}

The prevalence of ever and current use of tobacco among the cohort subjects in eighth grade is shown in table l. Ever use of cigarettes only was almost twice as frequent among girls compared to boys, while the reverse was true for exclusive snus use. This sex difference was also evident for current use, both among adolescents and parents (table 2). Maternal current use of snus was in fact a very rare behaviour; therefore the analysis was not possible for all outcome categories. Tables 3 and 4 present model based adjusted ORs of adolescents' current use of tobacco according to parental use. The estimates are adjusted for the other parent's tobacco use, as it was the only factor that revealed at least a modest confounding effect. In particular, adjusting for sex, age or tobacco use among friends did not materially modify the results.

Exposure to parental tobacco use increased the likelihood of current tobacco use among adolescents (table 3), with a hint of dose-response effect according to whether one or both parents used tobacco. However, the association differed according 
Table 3 Parental current tobacco use at baseline as risk factor for adolescents' any current use of cigarettes and snus in the eighth grade

\begin{tabular}{|c|c|c|c|c|c|c|}
\hline \multirow[b]{2}{*}{ Exposure to: } & \multicolumn{2}{|c|}{ Snus (boys) } & \multicolumn{2}{|c|}{$\begin{array}{l}\text { Cigarettes } \\
\text { (both sexes) }\end{array}$} & \multicolumn{2}{|c|}{$\begin{array}{l}\text { Any use } \\
\text { (both sexes) }\end{array}$} \\
\hline & OR & $95 \% \mathrm{Cl}$ & OR & $95 \% \mathrm{Cl}$ & OR & $95 \% \mathrm{Cl}$ \\
\hline \multicolumn{7}{|l|}{ Mother's tobacco use * } \\
\hline No tobacco use & 1.0 & & 1.0 & & 1.0 & \\
\hline Only snus & 2.2 & 0.5 to 10.9 & 0.5 & 0.1 to 3.6 & 1.3 & 0.4 to 4.4 \\
\hline Only cigarettes & 1.7 & 0.9 to 2.9 & 2.2 & 1.5 to 3.1 & 2.2 & 1.6 to 3.0 \\
\hline Both cigarettes and snus & 2.4 & 0.3 to 22.5 & 2.8 & 0.6 to 13.6 & 3.4 & 0.9 to 13.5 \\
\hline \multicolumn{7}{|l|}{ Father's tobacco use * } \\
\hline No tobacco use & 1.0 & & 1.0 & & 1.0 & \\
\hline Only snus & 2.4 & 1.3 to 4.4 & 1.0 & 0.6 to 1.6 & 1.4 & 0.9 to 2.0 \\
\hline Only cigarettes & 1.6 & 0.8 to 3.1 & 1.4 & 0.9 to 2.1 & 1.4 & 0.9 to 2.0 \\
\hline Both cigarettes and snus & 2.3 & 0.9 to 5.5 & 1.3 & 0.7 to 2.4 & 1.5 & 0.9 to 2.7 \\
\hline \multicolumn{7}{|l|}{ Parents' use of tobacco } \\
\hline Neither parent & 1.0 & & 1.0 & & 1.0 & \\
\hline One parent & 1.3 & 0.7 to 2.3 & 2.1 & 1.5 to 3.0 & 2.0 & 1.5 to 2.8 \\
\hline Both parents & 3.7 & 2.1 to 6.8 & 2.1 & 1.3 to 3.2 & 2.7 & 1.8 to 3.9 \\
\hline
\end{tabular}

Table 4 Parental current tobacco use at baseline as risk factor for adolescents' current use of tobacco in the eighth grade

\begin{tabular}{|c|c|c|c|c|c|c|}
\hline \multirow[b]{2}{*}{ Exposure to: } & \multicolumn{2}{|c|}{$\begin{array}{l}\text { Only snus } \\
\text { (boys) }\end{array}$} & \multicolumn{2}{|c|}{$\begin{array}{l}\text { Only cigarettes } \\
\text { (both sexes) }\end{array}$} & \multicolumn{2}{|c|}{$\begin{array}{l}\text { Both cigarettes } \\
\text { and snus (boys) }\end{array}$} \\
\hline & OR & $95 \% \mathrm{Cl}$ & OR & $95 \% \mathrm{Cl}$ & OR & $95 \% \mathrm{Cl}$ \\
\hline \multicolumn{7}{|l|}{ Mother's tobacco use * } \\
\hline No tobacco use & 1.0 & & 1.0 & & 1.0 & \\
\hline Only snus & 4.2 & 0.8 to 21.4 & 0.7 & 0.1 to 5.7 & - & - \\
\hline Only cigarettes & 1.8 & 0.8 to 4.0 & 2.4 & 1.6 to 3.6 & 1.7 & 0.7 to 3.8 \\
\hline $\begin{array}{l}\text { Both cigarettes and snus } \\
\text { Father's tobacco use* }\end{array}$ & 4.5 & 0.5 to 43.7 & 1.9 & 0.2 to 16.1 & - & - \\
\hline No tobacco use & 1.0 & & 1.0 & & 1.0 & \\
\hline Only snus & 3.0 & 1.4 to 6.4 & 1.1 & 0.6 to 1.8 & 1.4 & 0.5 to 3.8 \\
\hline Only cigarettes & 1.2 & 0.4 to 3.6 & 1.3 & 0.8 to 2.1 & 2.0 & 0.8 to 5.2 \\
\hline Both cigarettes and snus & 1.9 & 0.5 to 6.9 & 1.1 & 0.5 to 2.3 & 2.9 & 0.9 to 9.3 \\
\hline \multicolumn{7}{|l|}{ Parents' use of tobacco } \\
\hline Neither parent & 1.0 & & 1.0 & & 1.0 & \\
\hline One parent & 1.3 & 0.6 to 3.0 & 2.4 & 1.6 to 3.5 & 1.3 & 0.6 to 3.0 \\
\hline Both parents & 4.6 & 2.1 to 10.2 & 2.2 & 1.3 to 3.6 & 3.1 & 1.3 to 7.5 \\
\hline
\end{tabular}

to sex of the parent and tobacco product. Both maternal and paternal use of snus was associated with boys' current use of the same tobacco product, although only the association with father's use reached statistical significance. Maternal (but not paternal) current cigarette smoking was associated with a more than twofold increase in the risk of current smoking, especially exclusive smoking (table 4). An indication of a nearly threefold higher risk of combined use of cigarettes and snus among boys (OR 2.9, 95\% CI 0.9 to 9.3 ) was seen for boys whose fathers used both tobacco products compared to boys of non-tobacco users. Ever use of both cigarettes and snus among adolescents were associated with both maternal (OR 2.0, 95\% CI 1.5 to 2.7) and paternal cigarette smoking (OR 1.9, 95\% CI 1.3 to 2.6 ), as well as with paternal use of snus (OR 1.8, 95\% 1.3 to 2.5 ) (data not shown).

The prevalence of current smoking among adolescents was also compared between children of ever smoking fathers according to their current use of cigarettes and snus (currently not smoking and no snus use, currently not smoking but uses snus, currently smoking but no snus use, currently smoking and uses snus). The proportions of adolescent smokers (either exclusively or in combination with snus) was not substantially different in the four groups, if anything lowest among fathers who did no longer smoke but used snus. For all adolescents' outcomes there was an indication of dose-response according to whether one or both parents used tobacco. However, there was no clear dose-response relation according to frequency of parental tobacco use (whether occasional or daily). The analysis of adolescents' lifetime exposure to parental tobacco use yielded very similar risk estimates for most tobacco use outcomes (data not shown).

\section{DISCUSSION}

The purpose of this study was twofold. On the one hand, we aimed to increase the knowledge about parental influences on ST use among youth. On the other, we wanted to include in our analysis behavioural cross effects (that is, how the parental use of a certain tobacco product affects the adolescent use of the other). This issue has seldom been systematically investigated, ${ }^{5}$ and is of particular relevance in Sweden, where cigarette smoking and snus use are equally prevalent among adult males.

In this cohort, paternal use of snus was associated with an increased risk of snus use among boys, but not with the risk of adolescents being smokers. In contrast, both maternal and paternal smoking increased the probability of adolescents' cigarette smoking. Neither maternal nor paternal exclusive smoking increased the risk of exclusive snus use among their boys. The association between paternal snus use and corresponding use among boys in this study is in line with previous reports. ${ }^{14}$ At odds with other studies, however, we did 
not find an association between parental smoking and children's use of snus. ${ }^{15} 16$ This was true for both lifetime and current use. The interpretation of these findings should take into account Sweden's peculiar position in the market and consumption of $\mathrm{ST}^{17}$ as well as the different social norms around cigarette smoking and ST use. The findings in this study may therefore not apply to adolescent populations in other countries.

The Swedish variety of ST (snus) is increasingly attracting popularity as a "safer" alternative to cigarettes, and even considered as a potential aid in strategies of "harm reduction" directed to smoking populations. ${ }^{11}$ Adolescent boys, living in families where at least one parent (usually the father) shifts from smoking to snus might therefore consider this behaviour as a "healthy" and even socially acceptable choice. Consequently, they may be prompted to add snus to cigarettes in the very early experimental stage of tobacco use, but eventually to complete the transition to exclusive use of ST. It is also plausible that the availability of snus within the family provides the opportunity for a more extensive experimentation with tobacco in general. This influence, however, is likely to be confined to the earliest experimental stage, as paternal snus use was not significantly associated with the risk of current smoking, either alone or in combination with snus. In other terms, the overall prevalence of current smokers was not different between children of snus-using fathers than among children of non-tobacco users.

Parental influences in this study showed a gradient according to whether only one or both parents used tobacco. However, no increased risk of taking up tobacco was present among the offspring of parents using tobacco daily rather than occasionally. Misclassification of the frequency of tobacco use among parents is one explanation for this lack of doseresponse. An alternative explanation may be that children look upon recreational tobacco use among their parents as a positive trait. In fact, the social norms surrounding heavy and addicted smoking behaviour are increasingly negative in Sweden, especially when minors are involved. ${ }^{18}$ The social stigma attached to occasional smoking and "chippers" is probably not as strong, and it is possible that adolescents perceive adults smoking occasionally as people in control of their own behaviour. The generally stronger associations of parental behaviour with youths' current use compared to lifetime use is not surprising, considering the fact that the trial stage of tobacco use is nearly universal, therefore the risk factors may be less specific. In this study there were some evident sex differences concerning parental influences. Mother's smoking showed generally stronger associations with adolescent use of cigarettes than father's smoking as in other studies. ${ }^{15}$ Maternal educational and modelling influences are believed to be particularly strong in the adoption of health behaviours. ${ }^{19}$ However, our finding most probably reflects a societal dimension, as the smoking rates to date are higher among Swedish women than among Swedish men, while very few women use snus regularly.

Both adolescents' and parental behaviour were self reported; therefore the subjects in this study may have consciously concealed or minimised their smoking status. We used the self reported information on parental behaviour, rather than that available from the adolescents questionnaires, because the former was more detailed and had a higher internal response rate. Misclassification might also have occurred because of insufficient definition of, for instance, occasional smoking. Any misclassification of smoking status, if not differential, would rather bias the estimates in this study in a conservative way-that is, towards the null hypothesis. In addition, the prevalence of tobacco use at baseline in the cohort was very similar to that reported in Swedish cross sectional surveys both of adolescents, and of adults in the corresponding age and socioeconomic groups. ${ }^{7}$ A further limitation of the present analysis is the young age of the cohort, which

\section{What this paper adds}

The existence of a relationship between parental tobacco use and tobacco use among children and adolescents has been shown in a large body of published research. There has been no thorough investigation of cross effects of smoking and smokeless tobacco use between adults and their offspring.

This study of 2232 Swedish adolescents and their parents was conducted in a setting where smokeless tobacco (snus) is gaining popularity as a "safer" alternative to cigarette smoking. In such a setting, the exposure to parental smokeless tobacco use, although probably increasing the overall tobacco experimentation among adolescents, does not necessarily affect the transition from experimental to regular smoking.

does not allow the generalisation of the findings to late adolescents. The advantages of this study are its large size, the longitudinal design, and the detailed assessment of both smoking and ST use.

We suggest different influences of parental smoking and ST use on offspring's behaviour. Parental smoking is undoubtedly linked to the corresponding behaviour in children. On the other side, parental use of ST seem to enhance the overall rate of tobacco experimentation in youth, while the transition from experimental to regular cigarette use is apparently not influenced. Contextual factors, such as anti-smoking policy and changing social norms, are most probably of major importance in modelling family influences. These findings should be carefully considered when discussing policies of "harm reduction" directed to adults, in particular parents of children in school age.

\section{ACKNOWLEDGEMENTS}

The present study was entirely funded by the Center for Tobacco Prevention, Stockholm Center of Public Health, Stockholm County Council.

\section{Authors' affiliations}

*K I Rosendahl, A Ahlbom, Division of Epidemiology, Institute of Environmental Medicine, Karolinska Institute, Stockholm, Sweden M R Galanti, H Gilliam, Center for Tobacco Prevention, Stockholm Center of Public Health, Stockholm County Council, Stockholm, Sweden

*Also Center for Tobacco Prevention, Stockholm Center of Public Health

\section{REFERENCES}

1 Rossow I, Rise J. Concordance of parental and adolescent health behaviors. Soc Sci Med 1994;38:1299-305.

2 Tyas SL, Pederson LL. Psychosocial factors related to adolescent smoking: a critical review of the literature. Tobacco Control 1998;7:409-20.

3 Simon TR, Sussman S, Dent CW, et al. Correlates of exclusive or combined use of cigarettes and smokeless tobacco among male adolescents. Addict Behav 1993:18:623-34.

4 Murray DM, Roche LM, Goldman Al, et al. Smokeless tobacco use among ninth graders in a north-central metropolitan population: cross-sectional and prospective associations with age, gender, race, family structure, and other drug use. Prev Med 1988;17:449-60.

5 Horn KA, Gao X, Dino GA, et al. Determinants of youth tobacco use in West Virginia: a comparison of smoking and smokeless tobacco use. Am J Drug Alcohol Abuse 2000;26:125-38.

6 Cohen RY, Sattler J, Felix MR, et al. Experimentation with smokeless tobacco and cigarettes by children and adolescents: relationship to beliefs, peer use, and parental use. Am J Public Health 1987;77:1454-6.

7 Anon. Proportion of daily smokers in the adult population (18-70 years old). 1977-2000. Trends in alcohol and other drugs in Sweden. Report 2002. CAN: Centralförbundet för alkohol- och narkotikaupplysning; 2002:68:182-3.

8 Ramström LM. Snuff-an alternative nicotine delivery system. In: Ferrence R, Slade J, Room R, Pope M, eds. Nicotine and public health Washington: American Publich Health Association, 2000: 159-78.

9 Idris AM, Ibrahim SO, Vasstrand EN, et al. The Swedish snus and the Sudanese toombak: are they different? Oral Oncology 1998;34:558-66. 
10 Ahlbom A, Olsson UA, Pershagen G. Summary and conclusions: the health hazards of moist snuff. Health hazards of moist snuff. Stockholm: The National Board of Health and Welfare; 1997, 11:27-8.

11 Henningfield JE, Fagerstrom KO. Swedish Match Company, Swedish snus and public health: a harm reduction experiment in progress? Tobacco Control 2001:10:253-7.

12 Galanti MR, Rosendahl I, Post A, et al. Early gender differences in adolescent tobacco use - the experience of a Swedish cohort. Scand Public Health $2001 ; 29: 314-7$.

13 Bland M. Other multifactorial methods. An introduction to medical statistics, 3rd ed. Oxford: Oxford University Press; 2000:330.

14 Hall RL, Dexter D. Smokeless tobacco use and attitudes toward smokeless tobacco among Native Americans and other adolescents in the northwest. Am J Public Health 1988;78:1586-8.
15 Johnson CC, Li D, Perry CL, et al. Fifth through eighth grade longitudinal predictors of tobacco use among a racially diverse cohort: CATCH. J Sch Health 2002;72:58-64.

16 Lewis PC, Harrell JS, Deng S, et al. Smokeless tobacco use in adolescents: the cardiovascular health in children (CHIC II) Study. J Sch Health 1999:69:320-5.

17 Nordgren P, Ramstrom L. Moist snuff in Sweden-tradition and evolution. Br J Addict 1990;85: 1107-12.

18 Helgason AR, Lund KE. Environmental tobacco smoke exposure of young children- attitudes and health-risk awareness in the Nordic countries. Nicotine \& Tobacco Research 2001:3:341-5.

19 Andersen MR, Leroux BG, Marek PM, et al. Mothers' attitudes and concerns about their children smoking: do they influence kids? Prev Med 2002;34:198-206.

Study of the effectiveness of the US safety standard for child resistant cigarette lighters

\section{E Smith, M A Greene and H A Singh}

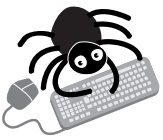

Please visit the Tobacco Control website for link to this full article-www. tobaccocontrol. com

Objective: The purpose of this research is to evaluate the effectiveness of the US Consumer Product Safety Commission's (CPSC) Safety Standard for Cigarette Lighters, which requires that disposable cigarette lighters be resistant to operation by children younger than age 5 .

Methods: Fire data on children playing with lighters were solicited from selected US fire departments for incidents occurring from 1997-99, to identify the proportion of such fires caused by children younger than age 5 playing with cigarette lighters. These data were compared with similar data from 1985-87. An odds ratio was used to determine if there was a significant decrease in cigarette lighter fires caused by children younger than age 5 compared to children ages 5 and older. To estimate fires that would have occurred without the standard, the odds ratio, adjusted for population, was applied to 1998 national estimates of fires occurring. National estimates of 1998 fire losses were based on data from the National Fire Incident Reporting System and the National Fire Protection Association to which the 1997-99 age and lighter type distributions were applied. The difference between the fire losses that would have occurred and those that did occur represented fire losses prevented.

Results: In the post-standard study, $48 \%$ of the cigarette lighter fires were started by children younger than age 5 , compared with $71 \%$ in the pre-standard study. The odds ratio of 0.42 was statistically significant $(\mathrm{p}<0.01)$. This represented a $58 \%$ reduction in fires caused by the younger age group compared to the older age group. When applied to national fire loss data, an estimated 3300 fires, 100 deaths, 660 injuries, and \$52.5 million in property loss were prevented by the standard in 1998, totaling $\$ 566.8$ million in 1998 societal savings.

Conclusions: The CPSC standard requiring child resistant cigarette lighters has reduced fire deaths, injuries, and property loss caused by children playing with cigarette lighters and can be expected to prevent additional fire losses in subsequent years.

\Inj Prev 2002;8:192-196 